\title{
Tribological application and mechanism of epicuticular wax
}

\author{
Xuwen ZHONG, Yanqiu XIA*, Xin FENG \\ School of Energy Power and Mechanical Engineering, North China Electric Power University, Beijing 102206, China \\ Received: 15 May 2017 / Revised: 20 July 2017 / Accepted: 02 September 2017 \\ (C) The author(s) 2017. This article is published with open access at Springerlink.com
}

\begin{abstract}
The plant cuticle is a complex mixture of omnipresent, commonly monofunctional, fatty acid derivatives and taxon-specific, generally bifunctional, specialty compounds. This study explored expanded applications for these substances. Four types of plant cuticles were distilled from leaves and the resulting lipid mixtures were analyzed using gas chromatography-mass spectrometry. These were then used as additives for a synthetic ester lubricant. A reciprocating friction and wear testing machine was utilized to investigate the resulting tribological properties. The worn surfaces of the lower discs were observed and analyzed using optical microscopy and time-of-flight secondary ion mass spectrometry. The results reveal that cuticular waxes can modify the friction properties of the base oil. Furthermore, cuticular waxes demonstrate better performance when compared to the commercially available additive molybdenum dithiocarbamates. A protective adsorption film was identified as the reason for the improved friction reduction and anti-wear properties of the lubricant on the friction pair. This study provides a reference for the study of new types of non-sulfur, phosphorus, and other active element additives and demonstrates considerable potential for the economical utilization of plant leaf waxes.
\end{abstract}

Keywords: epicuticular wax; tribological application; GC-MS; TOF-SIMS; adsorption

\section{Introduction}

The overwhelming majority of terrestrial flora has a layer of wax coating that serves to protect them from injuries and the surrounding environment [1]. This cuticle is the outermost hydrophobic layer that is non-cellular, and consists of cutin and waxes covering the external surfaces of plant leaves, flower petals, and non-woody stem organs. A series of biotic and abiotic stresses can be prevented by the cuticle, including water loss, bacterial and fungal pathogens, UV damage, particulate accumulation, low temperature injuries, and xenobiotic infiltration [2-5]. The precise composition of the cuticular wax is difficult to fully characterize. Furthermore, it is generally understood to be a mixture of several types of biogenic components. According to the results of prior research, the dominant constituents in most plants are very-long-chain saturated aliphatic compounds that may or may not have additional functional groups. The chemical compounds in the cuticular wax are mixtures of homologous series, with chain lengths typically ranging from 24 to 34 . The constituents of the wax can be separated into two groups: the first consists of fatty acids, primary alcohols, esters, and aldehydes; and the second consists of alkanes, secondary alcohols, and ketones [6]. The first group is characterized by even-numbered chain lengths, while the second group is typically dominated by odd-numbered chains. The composition and content of the cuticular waxes from different species can vary substantially [7]. For instance, in the plant waxes of some species, the content of alicyclic compounds such as triterpenoids can be highly dominant, and in some cases, it exceeds the amount of very-long chain (VLC) aliphatics present. The chemical structures and amounts of cuticular

* Corresponding author: Yanqiu XIA, E-mail: xiayq@ncepu.edu.cn 
wax compounds can vary significantly between plant species, between organs of the same species, between tissues of the same organ, and sometimes even between different compartments of the cuticle covering the same tissue [8-14]. Racovita et al. has performed comprehensive analyses of the cuticular wax on the leaf blade and peduncle of bread wheat (Triticum aestivum $\mathrm{cv}$. Bethlehem) and documented the presence of large amounts of 1 -alkanols, $\beta$-diketones, and hydroxy- $\beta$ diketones [15]. The wax mixtures of Aloe arborescens leaves have been found to contain VLC 3-hydroxy fatty acids, 3-hydroxy fatty acid methylesters, and 2-alkanols [9]. Busta et al. has identified the existence of $\beta$-hydroxy fatty acid esters and primary and secondary-alkanediol esters in the cuticular waxes of the moss Funaria hygrometrica [16].

Our previous research has examined adding cuticular wax into base oil as a lubricant additive and investigated the resulting influence on tribological properties. Xu et al. $[17,18]$ studied the lubricant properties of three types of plant waxes used as additives with a polyalphaolefin (PAO) base oil for aluminum-on-steel contact and found that these waxes possessed good friction reduction and anti-wear properties. Additionally, the surface waxes of leaves from two desert plants were extracted and determined to have excellent tribological properties when used as lubricant additives in PAO compared to molybdenum dithiocarbamate (MoDTC). Shi et al. [19] investigated the tribological properties of wheat leaf surface wax as an additive, and demonstrated its ability to improve friction reduction and anti-wear properties. In this study, cuticular waxes were extracted from four kinds of common ornamental plants and investigated when used as lubricant additives to base oil. An in-depth analysis of the wax chemical composition was performed, and the friction mechanism was elucidated.

\section{Experimental methods}

\subsection{Wax extraction}

Four epicuticular wax samples were used in these experiments: Sophora japonica (SJ), Photiniaxfraseri (PH), Pittosporum (PI), and Ilex chinensis (IC). Figure 1 shows images these four types of leaves.

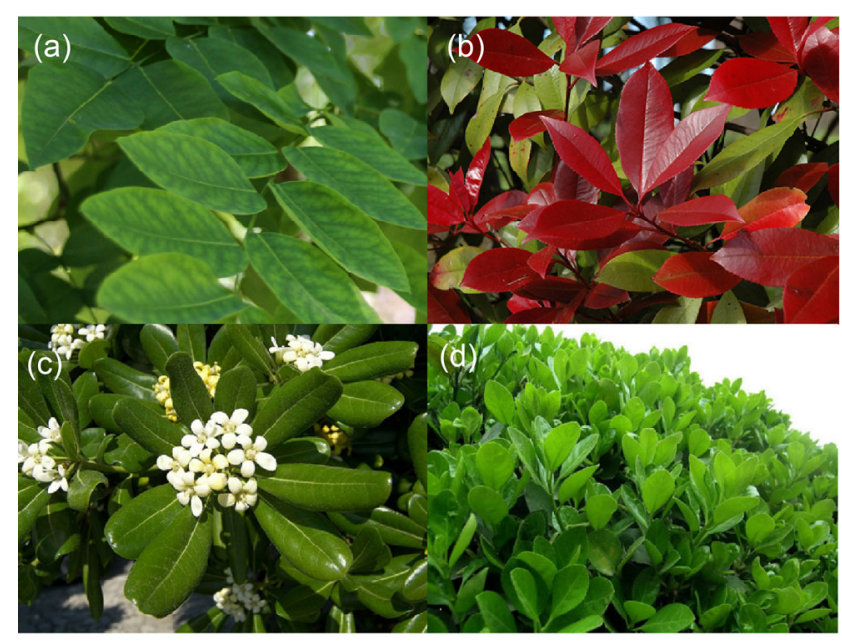

Fig. 1 Four types of plant leaves: (a) SJ; (b) PH; (c) PI; (d) IC.

Wax was extracted by the following series of steps: (1) pick and collect leaves; (2) wash the leaves with water and brush carefully and gently to remove any impurities without damaging the blade surface; (3) air-dry the leaves at room temperature; (4) steep the leaves in a chloroform solution (SJ leaves are very soft and thin; hence, they are bathed in the solution for 10 seconds, while the other leaves are bathed for 30 seconds); (5) let the solution completely volatilize in an exhaust ventilation system; (6) glean the precipitate.

The superficial characteristics of the four epicuticular waxes differ considerably, as shown in Fig. 2: SJ epicuticular wax is a powder, $\mathrm{PH}$ cuticular wax contains tiny bits of crystal plate, PI wax is a collection of slightly sticky particles, and IC wax contains gooey and irregular matter.

\subsection{Gas chromatography-mass spectrometry (GC- MS) analysis}

Analysis of the wax components was carried out on a $5890 \mathrm{~N}$ Network GC (Agilent). Each wax sample was injected on-column into a constant flow of $\mathrm{He}$ of $1.2 \mathrm{ml} / \mathrm{min}$. The GC oven was initially set at a temperature of $80^{\circ} \mathrm{C}$, followed by a $4{ }^{\circ} \mathrm{C} / \mathrm{min}$ ramp to $290{ }^{\circ} \mathrm{C}$, and then the temperature was maintained at $290{ }^{\circ} \mathrm{C}$ for $20 \mathrm{~min}$. A $5973 \mathrm{~N}$ Mass Selective Detector (EI $70 \mathrm{eV}$; ionization source temperature $230{ }^{\circ} \mathrm{C}$ ) was used to identify constituents in the cuticular wax mixtures. The compositions of the cuticular waxes are listed in Table 1. These results indicate that the 
(a)

(b)

(c)

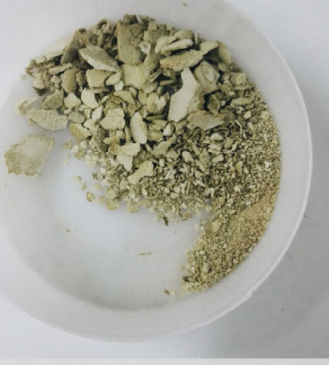

(d)

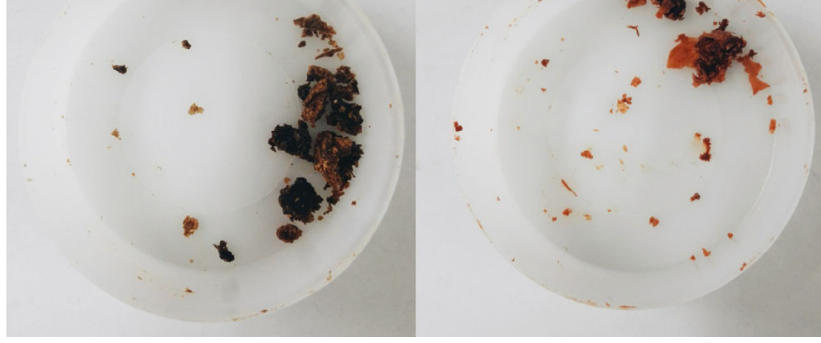

Fig. 2 Epicuticular waxes extracted from four different plants (a) SJ; (b) PH; (c) PI; (d) IC.

Table 1 Composition of four cuticular waxes.

\begin{tabular}{|c|c|c|c|c|}
\hline \multirow[b]{2}{*}{ Constituents } & \multicolumn{4}{|c|}{ Plant species } \\
\hline & SJ & $\mathrm{PH}$ & PI & IC \\
\hline Alkanes & $24.162 \%$ & $17.561 \%$ & $22.806 \%$ & $38.894 \%$ \\
\hline Acids & $0 \%$ & $0.414 \%$ & $3.974 \%$ & $2.372 \%$ \\
\hline Alcohols & $58.528 \%$ & $70.877 \%$ & $32.944 \%$ & $24.197 \%$ \\
\hline Esters & $1.658 \%$ & $6.619 \%$ & $2.908 \%$ & $6.346 \%$ \\
\hline Ketone & $0.601 \%$ & $3.767 \%$ & $1.238 \%$ & $8.629 \%$ \\
\hline
\end{tabular}

largest fractions of the cuticular wax components are alkanes and alcohols, which might affect the tribological properties. Thus, it is important to investigate the tribological performance of the different cuticular wax esusing friction tests to explore the influence of alkanes and alcohols.

\subsection{Preparation of lubricant}

Synthetic ester (SE) is a compound formed by the chemical reaction of fatty acids and alcohols that has been shown to perform as well as natural esters for lubrication. Furthermore, it has good thermal oxidation stability and dissolving capacity; hence, SE was chosen as the base oil for the tribological investigation in this study (SE obtained from Changsha Univic). Each type of cuticular wax was ultrasonically well-distributed in the base lubricant at weight percent concentrations of $0.5,1.0,1.5,2.0,2.5$, and $3.0 \mathrm{wt} \%$ (identified as 0.5 , 1.0, 1.5, 2.0, 2.5, 3.0-SJ-Oil, 0.5, 1.0, 1.5, 2.0, 2.5, 3.0-PH-Oil, 0.5, 1.0, 1.5, 2.0, 2.5, 3.0-PI-Oil, and 0.5, 1.0, 1.5, 2.0, 2.5, 3.0-IC-Oil, respectively). When these four types of waxes were used as additives in the base oil, lubricants of different viscosities were generated. The viscosity of each synthetic lubricant at $40{ }^{\circ} \mathrm{C}$ is listed in Table 2 . The results indicate that the viscosity of SE increases with the addition of cuticular waxes.

As further evidence, $0.5 \%$ MoDTC (0.5-MoDTC-Oil) was used as a control to determine whether epicuticular waxes can be applied as lubricant additives.

\subsection{Tribological tests}

An MFT-R4000 reciprocating friction and wear tester was utilized to obtain the tribological characteristics of the oil mixtures. All experiments were conducted at ambient temperature. For each test, the upper ball (hardness $710 \mathrm{Hv}$, diameter 5 mm, AISI 52100 steel) was pushed down with varying loads to touch the lower fixed discs (hardness 450-550 Hv, Ø24 mm × $7.9 \mathrm{~mm}$, AISI 52100 steel). The upper ball then moves back and forth in a $5-\mathrm{mm}$ stroke at a frequency of $5 \mathrm{~Hz}$ for 30 minutes. Prior to each test, the experimental materials were rinsed in a light petroleum to remove impurities and then $0.05 \mathrm{ml}$ of the mixing oil was added to the disc surface. A connected computer recorded real-time values for the coefficient of friction (COF). For each sample, three trials were conducted and the data was averaged. An optical microscope was used to gauge the wear scar widths (WSW).

\subsection{Abrasive surface study}

After the tribological experiments, all sample discs were dipped in acetone and washed using an ultrasonic washer. The wear tracks on the discs were analyzed

Table 2 Viscosities of each synthetic lubricant $(\mathrm{mPa} \cdot \mathrm{s})$ at $40^{\circ} \mathrm{C}$.

\begin{tabular}{ccccccc}
\hline & \multicolumn{6}{c}{ Weight percent } \\
\cline { 2 - 7 } Kinds & $0.5 \%$ & $1 \%$ & $1.5 \%$ & $2 \%$ & $2.5 \%$ & $3 \%$ \\
\hline SJ & 28.47 & 34.17 & 34.50 & 41.12 & 44.23 & 52.45 \\
PH & 27.38 & 28.05 & 27.70 & 27.27 & 31.94 & 30.28 \\
PI & 26.99 & 29.31 & 36.08 & 34.05 & 38.83 & 36.07 \\
IC & 28.62 & 28.75 & 31.76 & 31.85 & 31.21 & 31.47 \\
SE & \multicolumn{7}{c}{25.44} \\
\hline
\end{tabular}


with the help of a metallographic microscope (NikonLV 150N). Products formed on the friction surface were detected using a time-of-flight secondary ion mass spectrometry (TOF-SIMS) IV instrument. For static SIMS analysis (SSIMS), a Bi pulsed ion beam with a $30 \mathrm{keVvoltage}$ and $1.0 \mathrm{pA}$ energy was used for scanning an area of $200 \mu \mathrm{m} \times 200 \mu \mathrm{m}$ on the sample surface. Both negative and positive ion SSIMS spectra were obtained from the scan area. Surface SSIMS images of secondary ions present on the spectra were also acquired with resolutions of $256 \times 256$ pixels. TOF-SIMS can provide much more information than can be obtained by X-ray photoelectron spectroscopy (XPS) [20] because SSIMS can obtain chemical data from depths of $0.1-1 \mathrm{~nm}$ below the surface. In comparison with typical spectroscopic techniques such as XPS, Auger electron spectroscopy, and X-ray absorption near edge structure, TOF-SIMS can provide significantly more near-surface chemical information.

\section{Results}

\subsection{Analysis of cuticular wax compositions}

GC-MS was used to elucidate the composition of the cuticular wax mixtures extracted from the leaves. Many ubiquitously found compounds were readily identifiable, and the results indicate that the extracts

(a)

$$
-2 \mathrm{An}-\mathrm{Ph}-\mathrm{Pl}-\mathrm{Cl}
$$

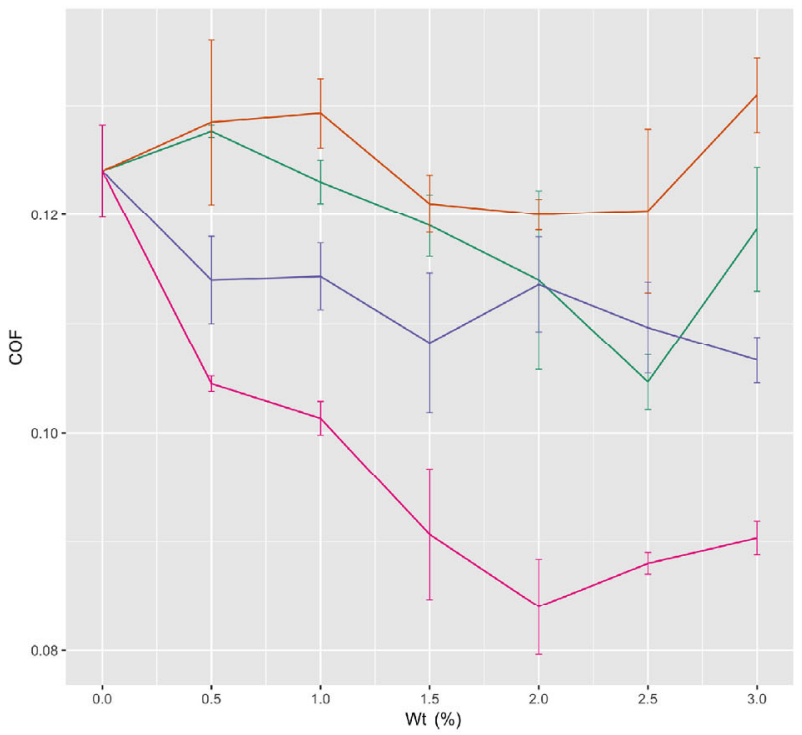

contain aliphatic, aromatic, and naphthenic compounds, with a large number of oxygen-containing groups.

\subsection{Tribological characteristics of different additives}

The friction and wear results from these experiments are presented in Figs. 3-5.

\subsubsection{Influence of wax additive contents on steel-steel friction pair}

Figure 3 shows the variation in the COF and WSW identified during experiments conducted at $50 \mathrm{~N}, 5 \mathrm{~Hz}$, and ambient temperature. When used as lubricant additives, the IC epicuticular wax demonstrates the best friction-reducing performance of the four waxes. The minimum COF of 0.084 occurs for an IC wax content of $2 \%$, which is $32.3 \%$ lower than the COF of 0.124 for SE wax. However, the anti-wear performance of IC is not good, and even when the wax content is $1.5 \%$ or $2 \%$, the WSWs of IC exceed those of SE. Epicuticular wax from $\mathrm{PH}$ does not improve the antifriction or anti-wear performance and its WSW value is larger than that of SE at $1 \%$. The PI cuticular wax improves the anti-friction property of SE, but produces more severe wear. The SJ epicuticular wax produces a $15.3 \%$ reduction in COF from 0.124 to 0.105 at a $2.5 \%$ wax content. SJ also shows improved anti-wear performance, as indicated by the apparent reduction

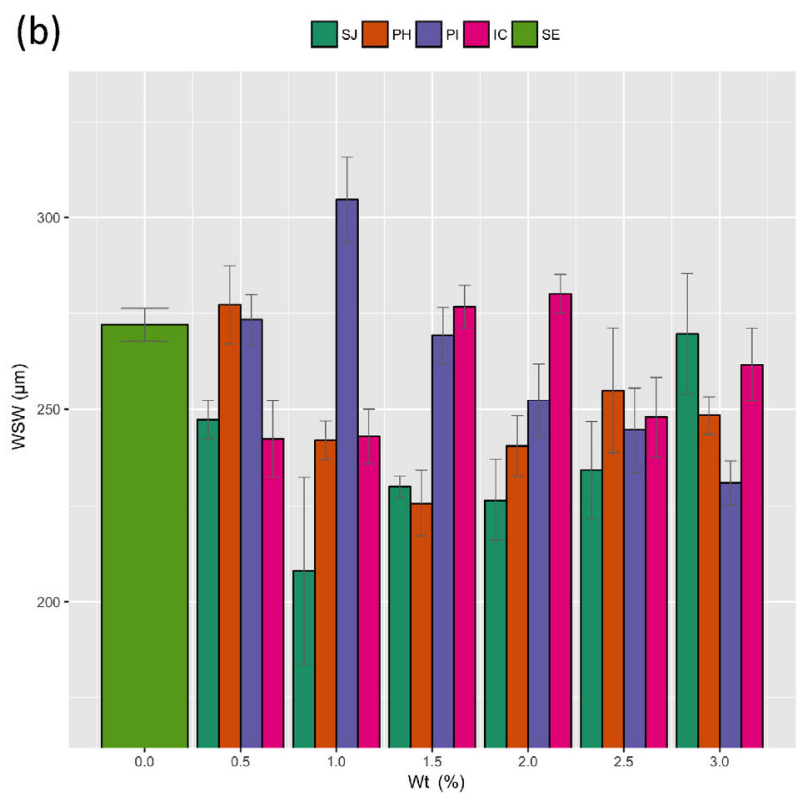

Fig. 3 Average (a) COF and (b) WSW for lubricants with different additive contents at ambient temperature $($ load $=50 \mathrm{~N}$; frequency $=5$ $\mathrm{Hz}$; stroke $=5 \mathrm{~mm}$; duration $=30 \mathrm{~min})$. 
(a)

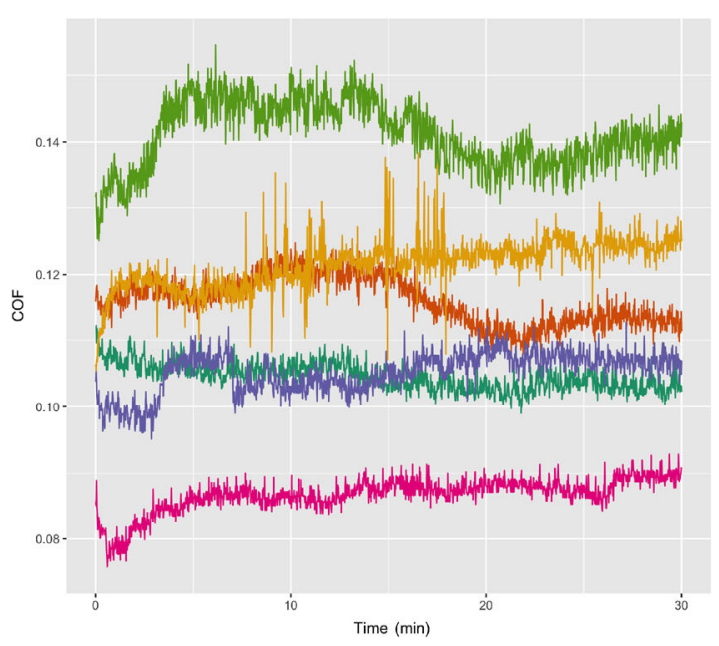

(b)

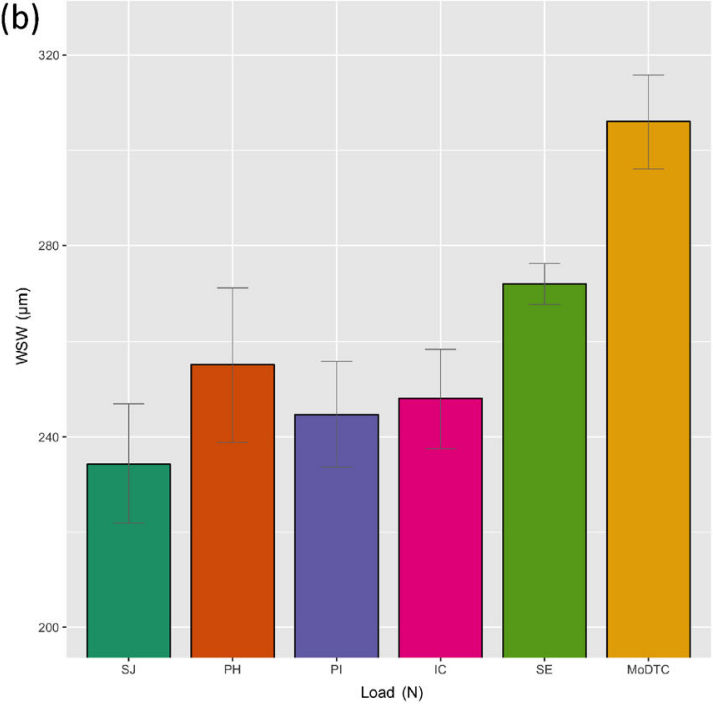

Fig. 4 (a) COF and (b) WSW for SE, 0.5\%-MoDTC, 2.5\%-SJ-Oil, 2.5\%-PH-Oil, 2.5\%-PI-Oil and 2.5\%-IC-Oil at ambient temperature (load $=50 \mathrm{~N}$; frequency $=5 \mathrm{~Hz}$; stroke $=5 \mathrm{~mm}$; duration $=30 \mathrm{~min}$ ).

(a)

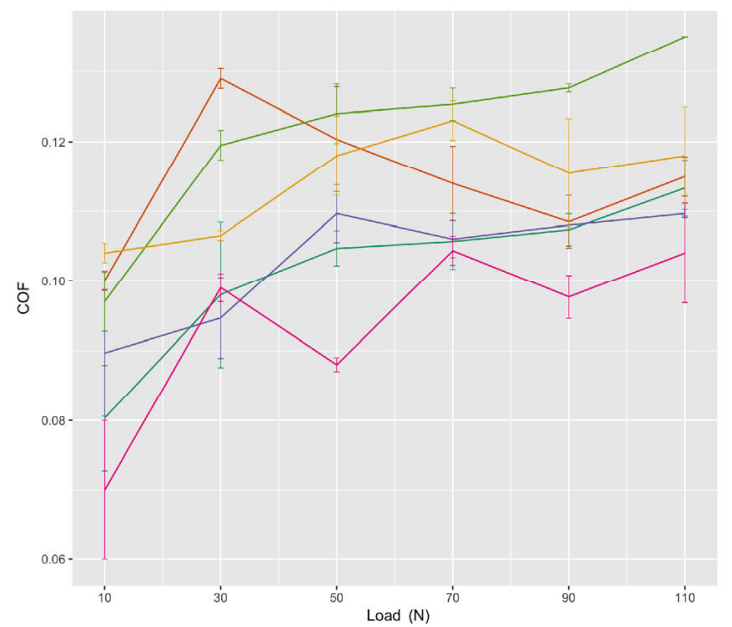

(b)
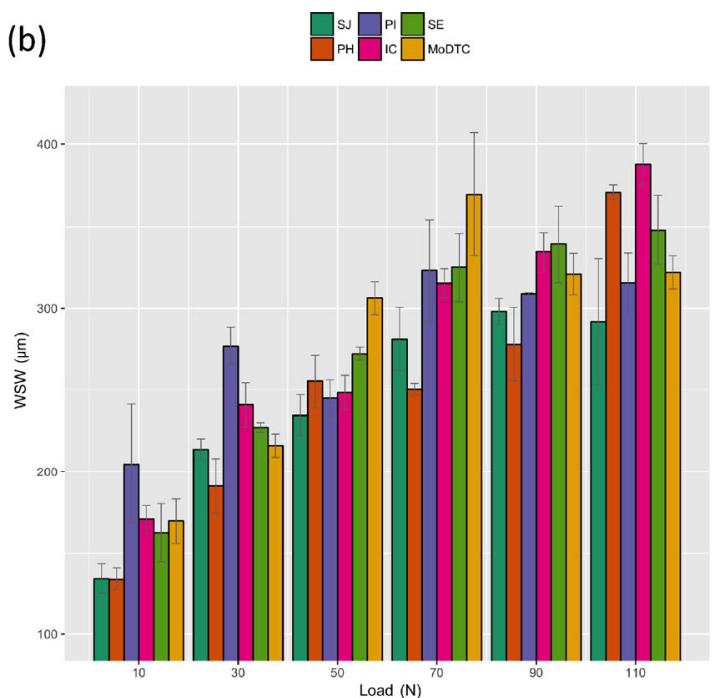

Fig. 5 Average (a) COF and (b) WSW for lubricants at varying workloads at ambient temperature (content=2. 5\%; frequency=5 Hz; stroke $=5 \mathrm{~mm}$; duration $=30 \mathrm{~min}$ ).

in the WSW for each wax content. Based on this analysis, the COF-reducing performance of IC is excellent, while SJ performs well for both anti-friction and anti-wear properties. Figure 3(a) shows that the COF values are higher for lower additive contents. The COF values of the four lubricants with wax contents of $0.5 \%$ and $1 \%$ are all higher than the lubricants that have wax contents of $1.5,2$, or $2.5 \%$. With an increasing wax content, the COF values increase. The wear resistances of each lubricant shown in Fig. 3(b) are not necessarily coincident with the friction resistances in Fig. 3(a). Figure 3(b) shows that the WSW values of 0.5-PH-Oil, 0.5-PI-Oil, 1-PI-Oil, 1.5-IC-Oil, and 2-IC-Oil are all larger than those for SE.

Figure 4 shows the friction coefficients and wear widths of the sliding pairs using SE, 0.5-MoDTC-Oil, 2.5-SJ-Oil, 2.5-PH-Oil, 2.5-PI-Oil, and 2.5-IC-Oil at a load of $50 \mathrm{~N}$ and a frequency of $5 \mathrm{~Hz}$ at room temperature. SE clearly has the highest COF values. The COF values obtained from the steel-steel contact increased as: $\mathrm{IC}<\mathrm{SJ}<\mathrm{PI}<\mathrm{PH}<\mathrm{MoDTC}<\mathrm{SE}$. The 2.5-IC-Oil has the best friction-reducing capability. The trend with 
2.5-SJ-Oil COF is more stable than the others, and it also has a relatively low COF value. Figure 4(a) demonstrates that these four types of leaf wax exhibited improved anti-friction performance for steel-steel contact. However, Fig. 4(b) indicates that not all the lubricant additives improve the anti-wear performance.

\subsubsection{Influence of load on steel-steel friction pair}

Figure 5 shows the mean COF and WSW values of the synthetic oil containing additives at $2.5 \mathrm{wt} \%$ for varying loads $(10-110 \mathrm{~N}$ at $20 \mathrm{~N}$ intervals). There is a positive correlation between both COF and WSW values and the workload. As the load increases, the COF of SE increases from 0.097 to 0.135 and the WSW increases from $0.163 \mathrm{~mm}$ to $0.348 \mathrm{~mm}$. Only 2.5-PH-Oil exhibits a higher COF than SE for a $30 \mathrm{~N}$ workload; all other additives have lower COF than SE and MoDTC for the same conditions, of which IC is the most effective. As seen in Fig. 5(b), IC, PH, and PI epicuticular waxes have adverse effects on WSW under certain conditions: 2.5-PH-Oil at $110 \mathrm{~N}$ workload; 2.5-PI-Oil at $10 \mathrm{~N}$ and $30 \mathrm{~N}$ workloads; and 2.5-IC-Oil at $10 \mathrm{~N}, 30 \mathrm{~N}$, and $110 \mathrm{~N}$ workloads all have WSWs greater than that of SE. Meanwhile, the 2.5-SJ-Oil demonstrates good wear resistance compared to that of SE.

\subsection{Surface analysis}

\subsubsection{Surface profile study}

The damage to the steel discs at the end of the experiments was examined with a metallographic microscope. The results for experiments with five different lubricants at $100 \mathrm{~N}$ load under both low and high magnification are shown in Fig. 6. It can be observed that smoother surfaces are obtained with lubrication using wax additives than with SE. Figures 6(a) and 6(b) show the surface of the disc lubricated with SE, which has a relatively matte face with the heaviest grooves along the gliding direction. Figures 6(e) and 6(f) show the surface of the disc lubricated with 2.5-PH-Oil, which has a crowded furrow distribution as a result of adhesive wear that is in accordance with the high COF for this lubricant shown in Fig. 5(a). Moreover, Figs. 6(e) and 6(i) display wider wear scars, correlating to the WSW data presented in Fig. 5(b). The 2.5-SJ-Oil and 2.5-PI-Oil lubricants have demonstrated relatively low friction and low wear properties (as shown in Fig. 5), and can be seen in the micrographs to have relatively fewer groves concentrated on both edges. The 2.5-IC-Oil lubricant exhibited the lowest COF, and it can be seen in Figs. 6(i) and 6(j) that the resulting surface has fine grooves along the sliding direction, illustrating a smaller contact area on the worn disc surface.
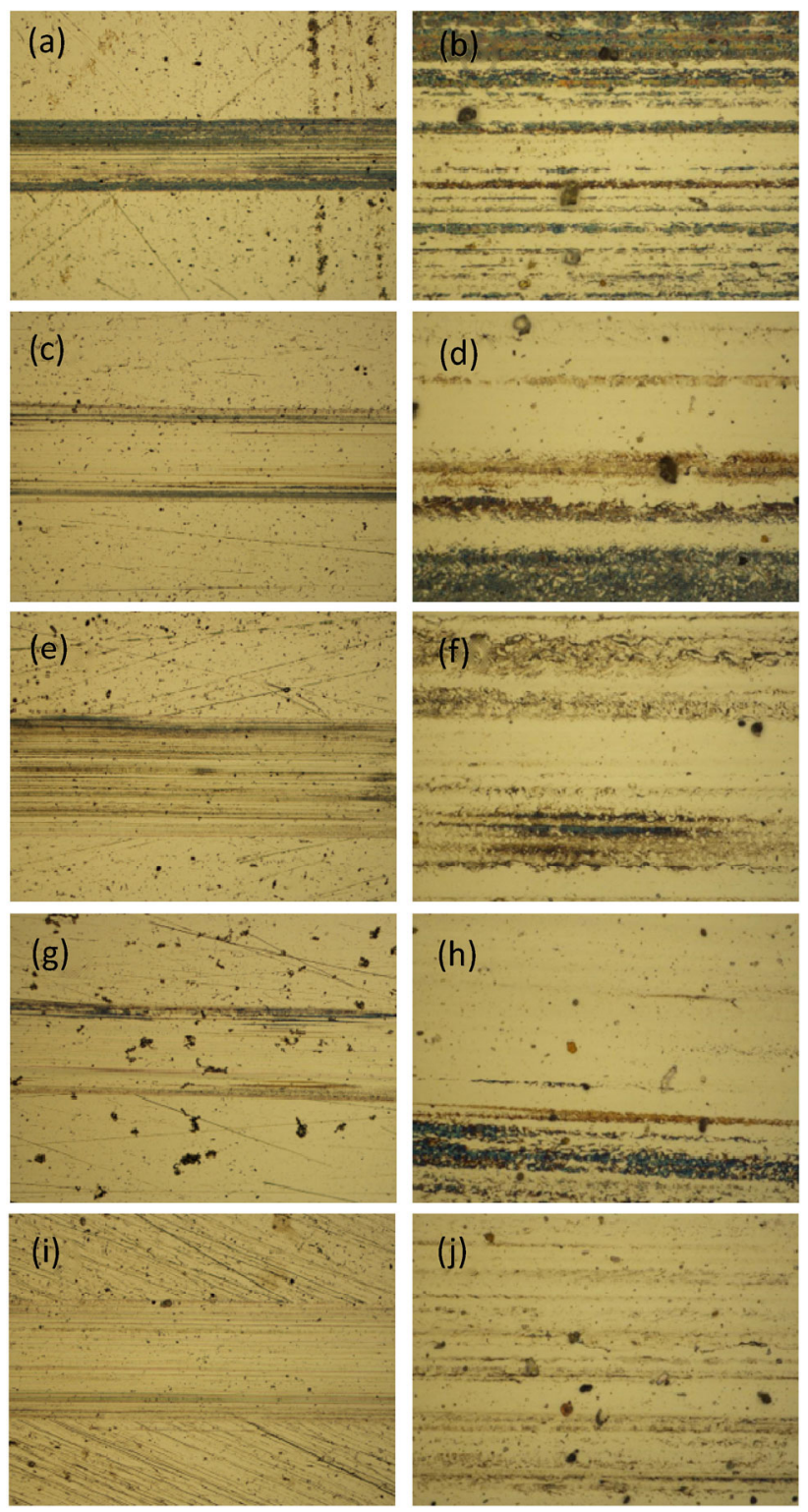

Fig. 6 Micrographs of the wear scar of steel discs lubricated with (a) SE at $100 \times$ magnification; (b) SE at $1000 \times$ magnification; (c) SJ at $100 \times$ magnification; (d) SJ at $1000 \times$ magnification; (e) $\mathrm{PH}$ at $100 \times$ magnification; (f) $\mathrm{PH}$ at $1000 \times$ magnification; (g) PI at $100 \times$ magnification; (h) PI at $1000 \times$ magnification; (i) IC at $100 \times$ magnification; (j) IC at $1000 \times$ magnification at $110 \mathrm{~N}$ load and $5 \mathrm{~Hz}$ frequency. 


\subsubsection{Chemical imaging using TOF-SIMS}

Positive and negative ion SSIMS spectra obtained for the grinding cracks lubricated by 2.5-SJ-Oil, 3-PI-Oil, and 2-IC-Oil are shown in Fig. 7. In Fig. 7, several characteristic peaks have been indexed and attributed to the presence of a variety of $\mathrm{C}_{x} \mathrm{H}_{y}$ and $\mathrm{C}_{x} \mathrm{H}_{y} \mathrm{O}_{z}$ ions arising from alkyl chains of the lubricants that have been previously identified. This suggests that some of the long carbon chains in the lubricants and additives have been broken down into smaller segments by friction. The positive ion figures indicate large amounts of iron ions, which are most abundant in Figs. 7(a) and $7(e)$. Figures 7(b), 7(d), and 7(f) show that a significant amount of anionic oxygen, hydroxyl groups, and very
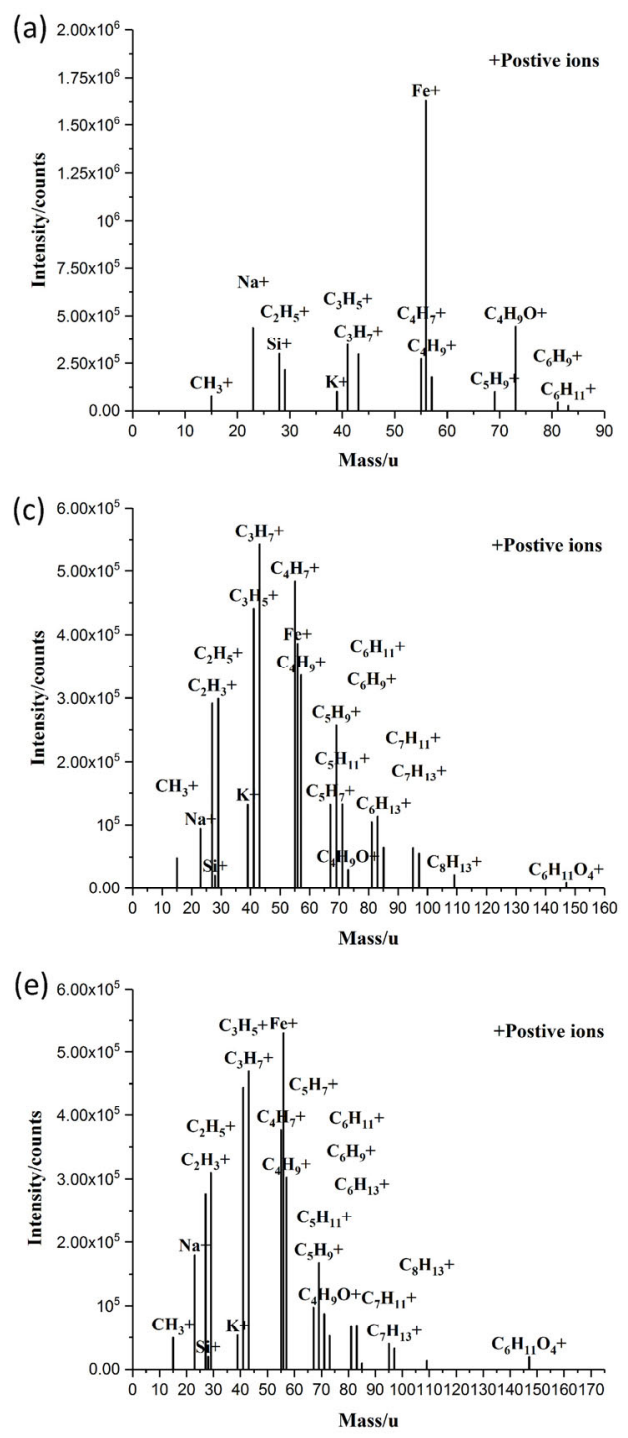

short carbon chain negative ions have been produced; anionic oxygen is most abundant in Fig. 7(b), while Fig. 7(f) indicates the presence of more very short chain alkyl negative ions.

Figure 8 shows the chemical images of positive and negative ions obtained from the TOF-SIMS analysis of a selected area of the abraded surfaces $(200 \mu \mathrm{m} \times$ $200 \mu \mathrm{m})$. Figures $8(\mathrm{a}), 8(\mathrm{c})$, and $8(\mathrm{e})$ are positive ions, while Figs. 8(b), 8(d), and 8(f) show negative ions. Different contents of positive and negative ions produce an effect on the brightness of chemical images, and a more prominent area indicates a higher level of the detected ion. The SSIM images show a valid relationship between positive and negative ion products
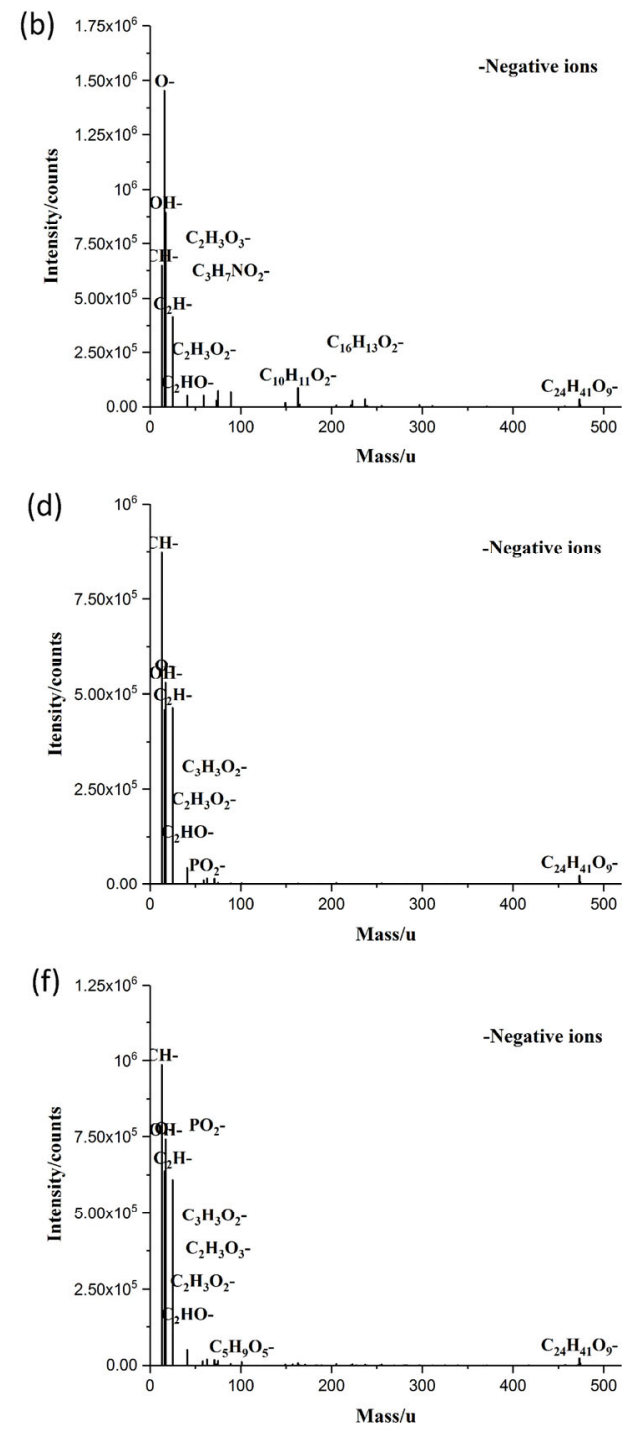

Fig. 7 TOF-SIMS spectra of positive and negative ions derived from 2.5-SJ-Oil ((a) and (b)), 3-PI-Oil ((c) and (d)), and 2-IC-Oil ((e) and (f)) tribofilms. 
(a)

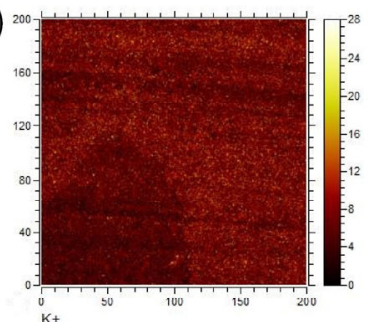

MC: $28 ;$ TC: $4.379 \mathrm{e}+005$

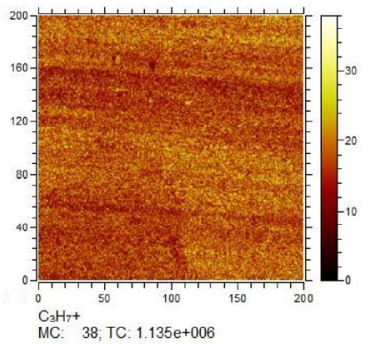

(b)

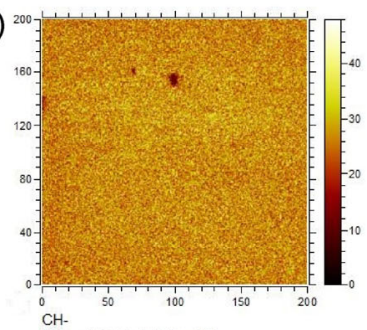

MC: $48 ;$ TC: $1.770 \mathrm{e}+006$

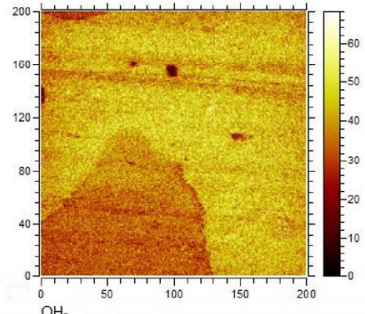

MC: $68 ;$ TC: $2.655 \mathrm{e}+006$

(c)
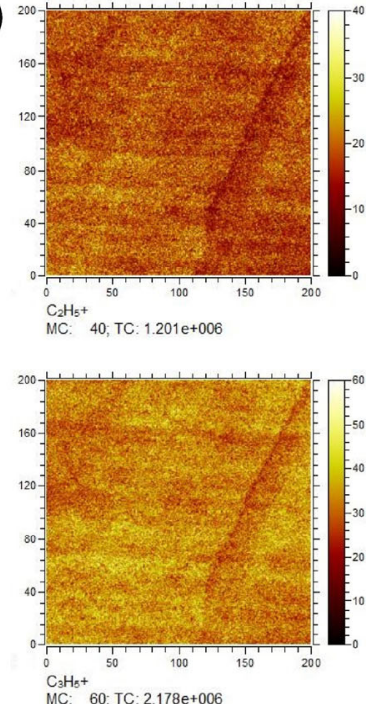

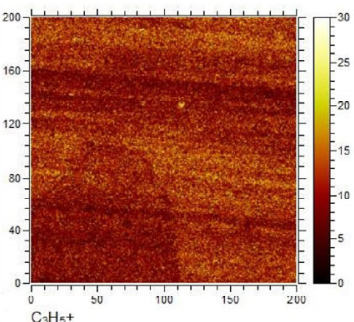

$\mathrm{C}_{3} \mathrm{H}_{5}{ }^{+}$
MC: $30 ; \mathrm{TC}: 6.923 \mathrm{e}+005$
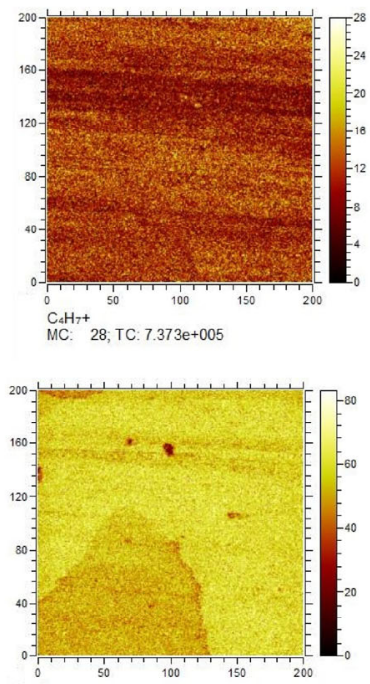

MC: 83 ; TC: $3.719 \mathrm{e}+006$

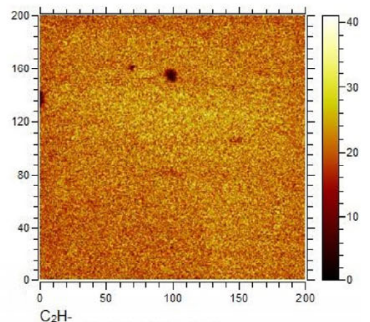

MC: $\quad 41 ;$ TC: $1.403 \mathrm{e}+006$

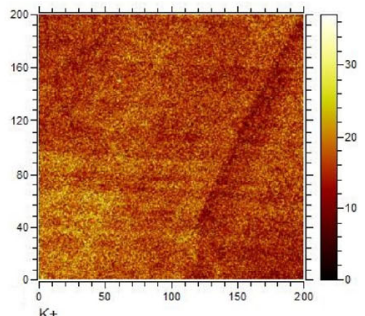

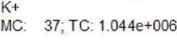

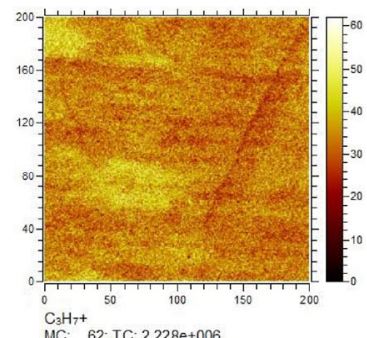

MC: 62; TC: $2.228 \mathrm{e}+006$

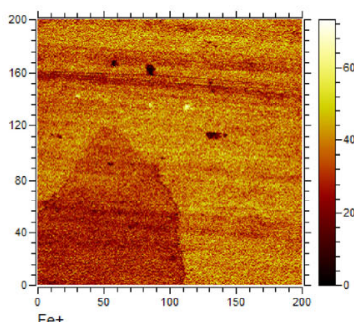

Fe+
MC: $73 ;$ TC: $2.332 \mathrm{e}+006$

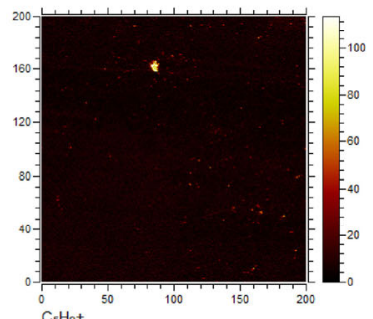

$\mathrm{C}_{5} \mathrm{H}_{\mathrm{H}}+$
MC:

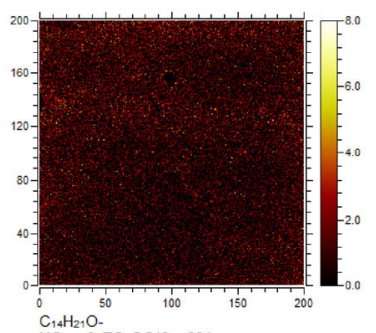

$\mathrm{C}_{14} \mathrm{H}_{2} 1 \mathrm{O}-$
MC:

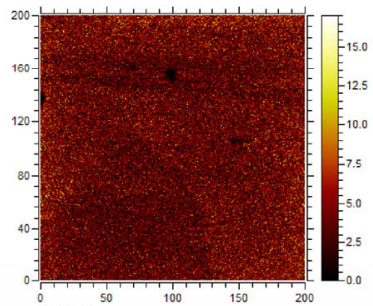

$\mathrm{C}_{414} \mathrm{H}_{7} \mathrm{O}_{3-}$
MC: $17 ; \mathrm{TC}: 2.598 \mathrm{e}+005$

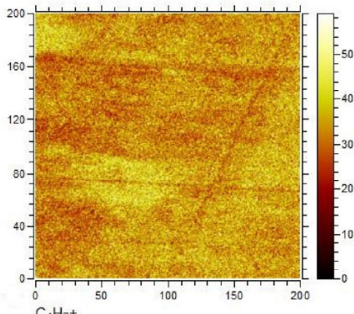

MC: $59 ;$ TC: $2.239 \mathrm{e}+006$

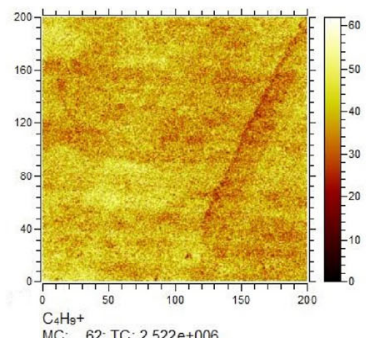

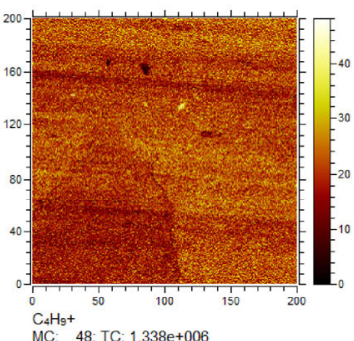

MC: 48 - TC: $1338 \mathrm{e}+000$
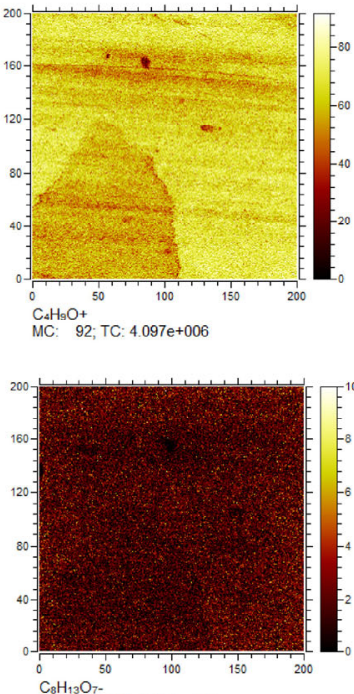

$\mathrm{C}_{8} \mathrm{H}_{13} \mathrm{O}_{7-}$
MC: $10 ; \mathrm{TC}: 1.127 \mathrm{e}+005$

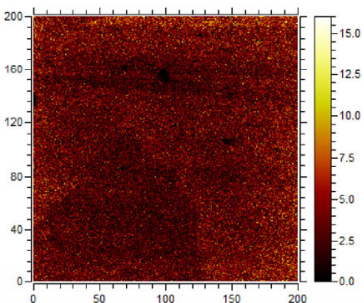

$\mathrm{C}_{16} \mathrm{H}_{13} \mathrm{O}_{2-}^{-}$
MC: $16 ;$ TC: $2.166 \mathrm{e}+005$

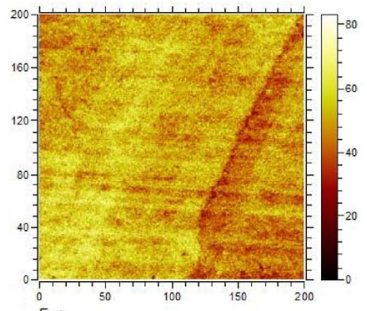

$\mathrm{Fe}+$
MC: $\quad 83 ;$ TC: $3.287 \mathrm{e}+006$

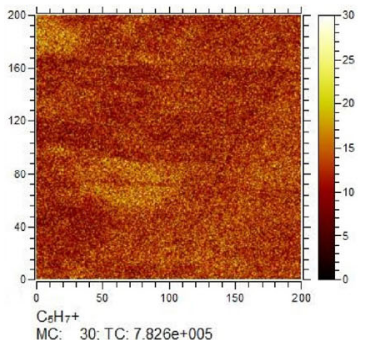

Fig. 8 SSIM images of positive and negative ions from a selected area of 2.5-SJ-Oil ((a) and (b)), 3-PI-Oil ((c) and (d)) and 2-IC-Oil ((e) and (f)) tribofilms at room temperature. 
(d)
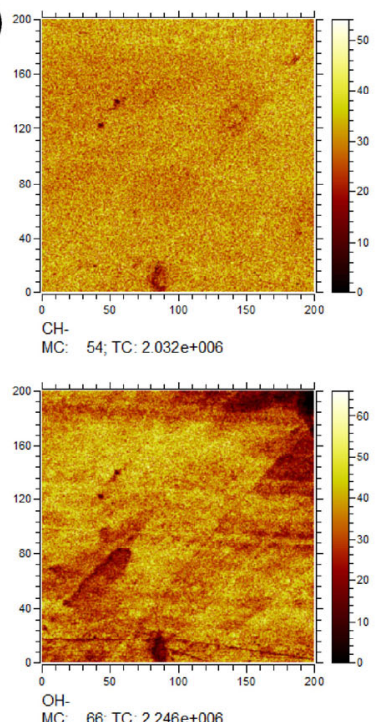

(e)

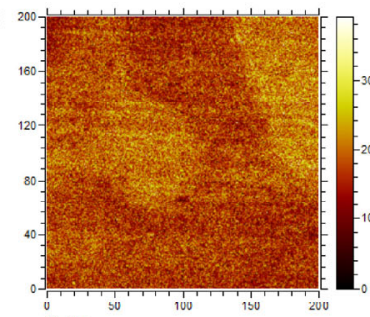

MC: 39; TC: $1.151 \mathrm{e}+006$

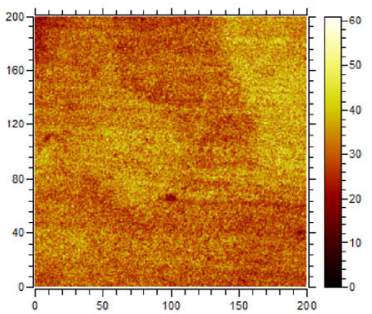

Colst
MC: $61 ;$ TC: $2.074+000$

(f)
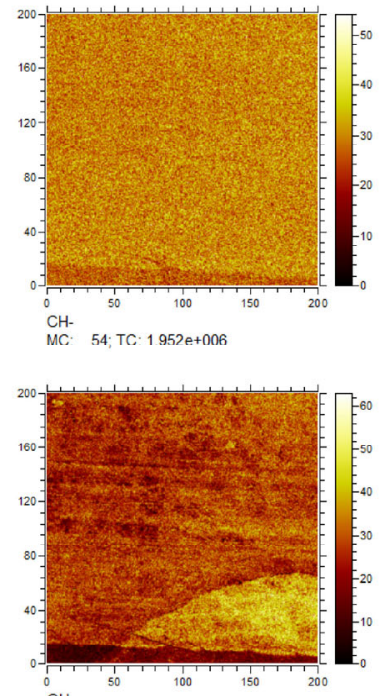

OH. 63 TC: 1.795e+006

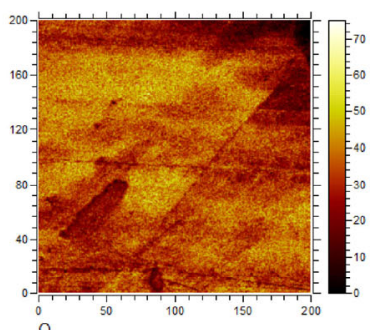

MC: $75 ;$ TC: $2168 \mathrm{e}+006$
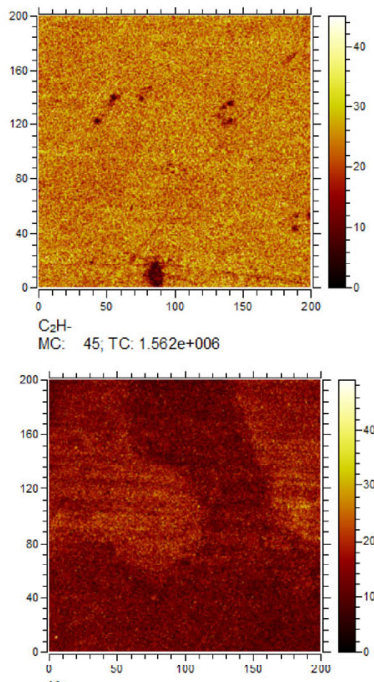

MC: 49 ; TC: $8.898 \mathrm{e}+005$

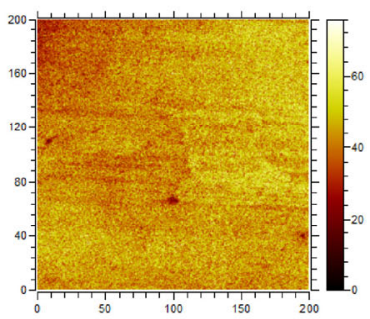

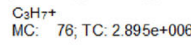

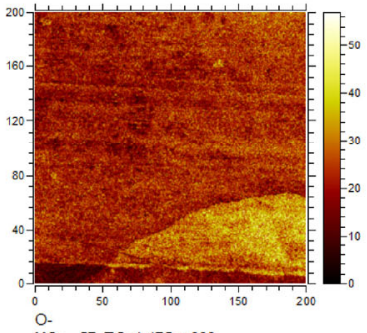

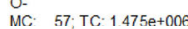

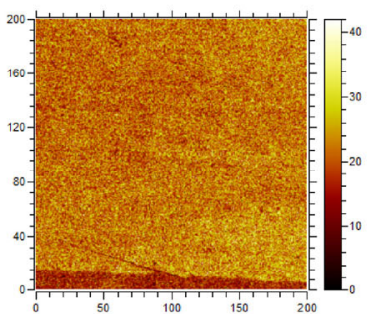

C.2.

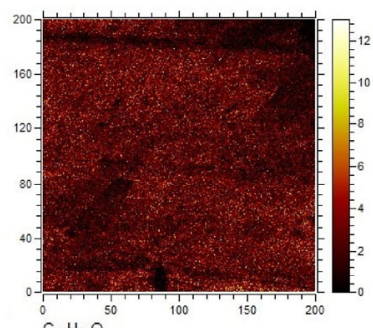

$\mathrm{C}_{14} \mathrm{H}_{2}=\mathrm{O}^{50}$
MC: $13 ; \mathrm{TC}: 1.638 \mathrm{e}+005$

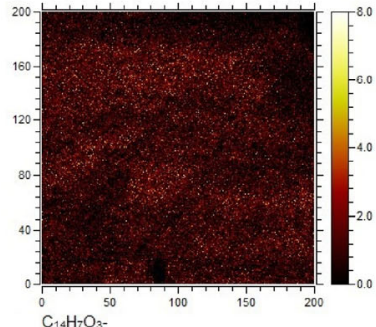

MC: $8 ; \mathrm{TC}: 6.636 \mathrm{e}+004$

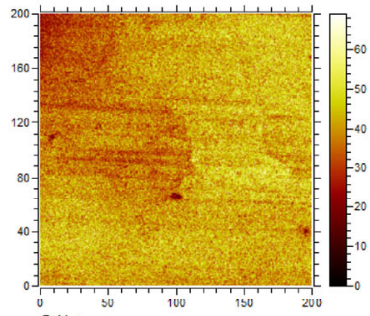

MC: $69 ;$ TC: $2.672 \mathrm{e}+006$

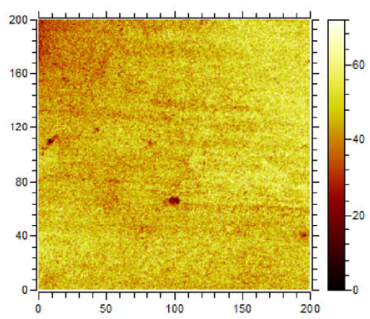

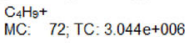

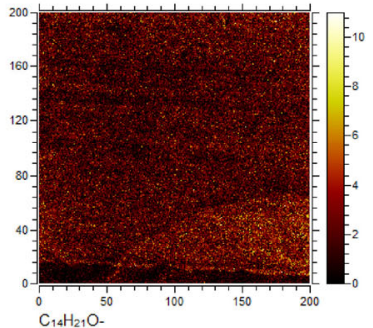

MC: $11 ;$ TC: $1248 \mathrm{e}+005$

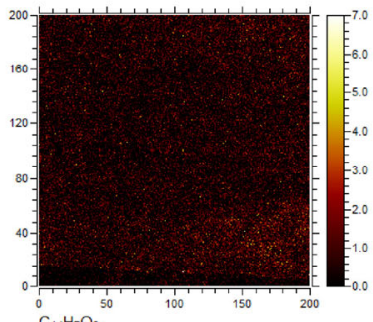

$\mathrm{C}_{14} \mathrm{H}_{7} \mathrm{O}_{3-}$
MC:

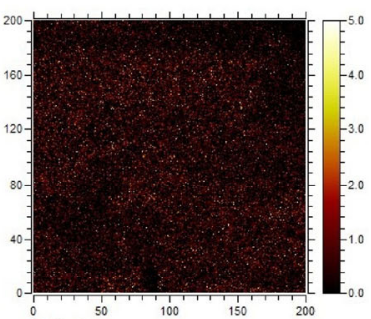

$\mathrm{C}_{8} \mathrm{H}_{13} \mathrm{O}_{7-}$
MC: $5 ; \mathrm{TC}: 2.694 \mathrm{e}+004$

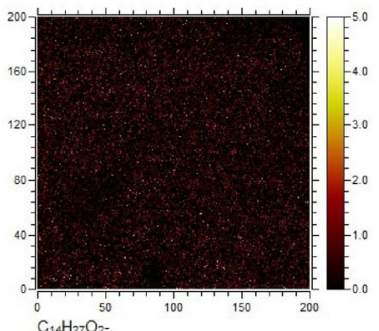

MC: ${ }_{11}$; TC: $1.989 \mathrm{e}+004$

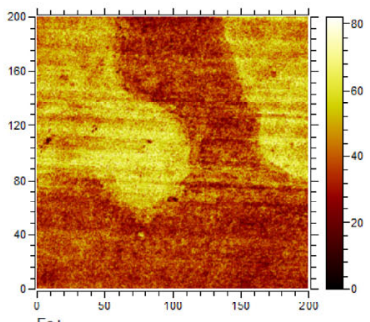

MC: $82 ;$ TC: $2.718 \mathrm{e}+006$

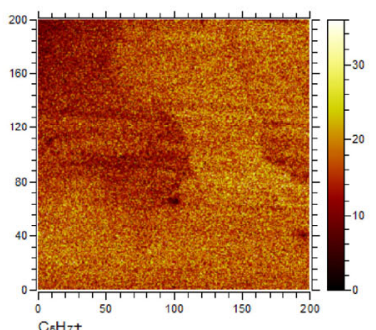

MC: 36 , TC: $1.050 \mathrm{e}+006$

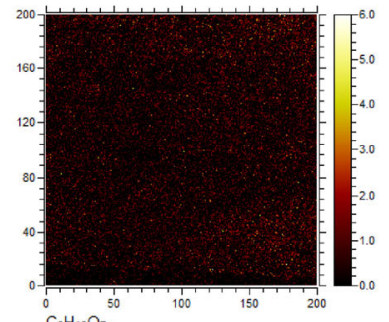

$\mathrm{C}_{8} \mathrm{H}_{13} \mathrm{O}_{7-}-$

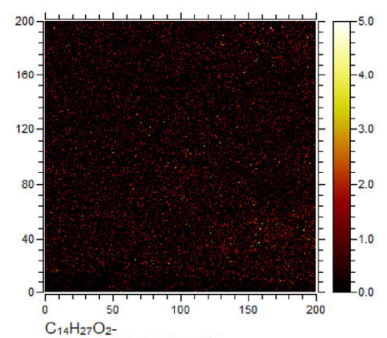

$\mathrm{C}_{14} \mathrm{H}_{27} \mathrm{O}_{2}-$
MC: $5: \mathrm{TC}: 1.474 \mathrm{e}+004$

Fig. 8 (Continued) 
on the wear surfaces. These TOF-SIMS spectra and chemical images show that the negative ions derived from anionic moieties are able to adsorb onto the metal surface through a chemical reaction and generate a tribofilm on the sliding surface that can improve the tribological properties.

\section{Discussion}

All experiments were conducted at room temperature $\left(20-25^{\circ} \mathrm{C}\right)$, and the lubricants functioned to improve friction-reducing and anti-wear capabilities mainly by forming a physical and chemical adsorbing film [21]. Physical adsorption results from van der Waals forces causing attraction between the lubricant molecules and the friction pair surface in which the molecules are arranged into monolayer or multilayer orders with no electron transfer. The cuticular waxes used in these experiments play the important role of surfactants because of their intrinsic amphiphilic properties, having one end that is the hydrophobic portion of a long-chain alkyl and the other end that is a hydrophilic $\mathrm{OH}$ group [22]. A surface adsorption layer is formed by the lubricant molecules, and then parallel hydrocarbon chains array tightly and form a molecular membrane as determined by the van der Waals interactions, shown in Fig. 9. Owing to the action of lateral cohesion, the strength of the adsorption film is enhanced and will not be easily punctured by the asperities inhibiting direct contact between the friction pair and will have the effect of lubrication.

Electron interchange between the polar molecules of the lubricants and the metal surface helps the lubricant molecules adsorb onto the surface with

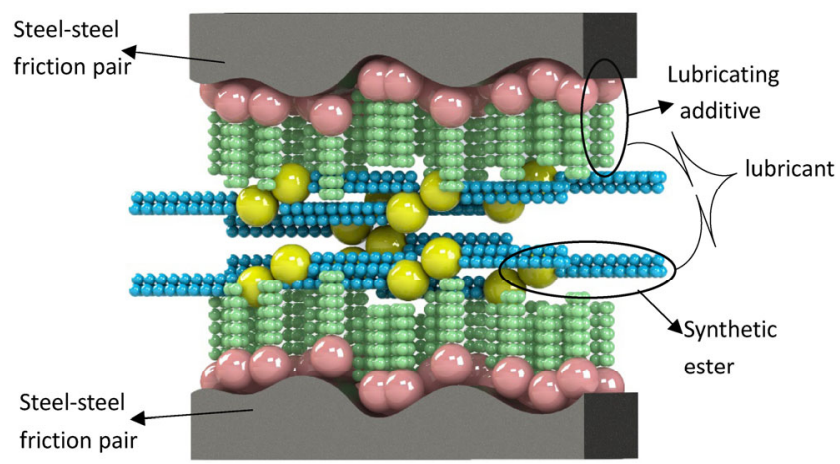

Fig. 9 Overview of physically adsorbed film. chemical bonds, as shown in Fig. 10. A chemical adsorption film is formed by the directional arrangement of polar molecules. Because of electron leakage from convex contact points on the metal surface during the sliding process, the metal surface carries a positive charge $[22,23]$. The lubricant anions adsorbed on the metal surface can produce a complex covering on the surface without desorption and fracture, reducing the contact area and providing a positive effect on the anti-friction and anti-wear functions. Adsorption between iron ions and negative ions such as oxygen anions creates a chemisorbed film with the synergistic effect of physical adsorption that contributes to reduction of abrasion.

$\mathrm{PH}$ is not suitable as lubricant additive because it contains a significant amount of heterocyclic compounds, as shown in the supporting information. The influence of adsorbing films containing polar organic compounds on surfaces sliding or rolling over each other is dependent on the structure of the adsorbed species: straight chain compounds with polar end groups perform better than either long chain compounds with the polar group in the middle of the chain or polar cyclic organic compounds [24]. The long chain alkane, alcohol, and ketone components of cuticular wax listed in Table 1 can protect the surface to some extent, and for these three types of compounds, a chemical adsorption film would be the dominant mechanism for reducing friction and wear [25]. Figures 3 and 5 demonstrate that SJ has good anti-friction and anti-wear performance, and as 1,

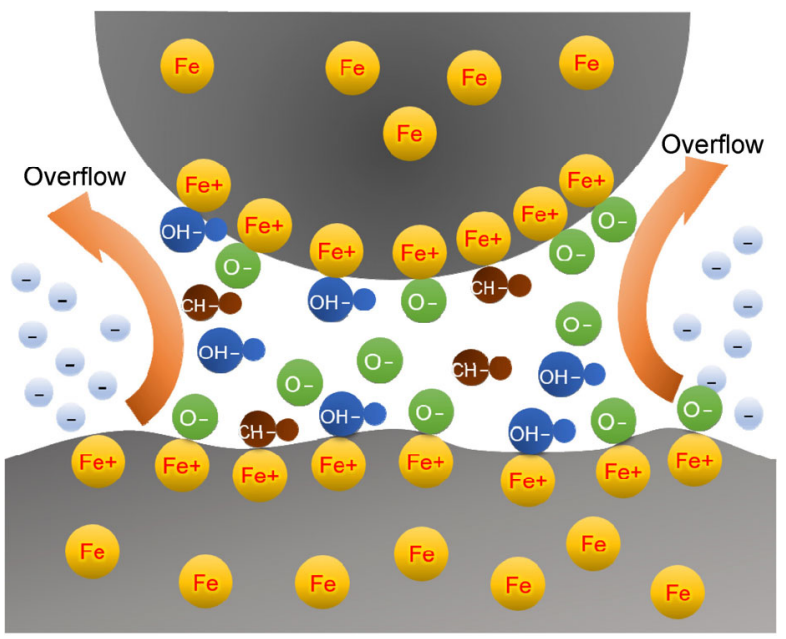

Fig. 10 Overview of chemically adsorbed film. 
30-Triacontanediol with a certain polarity is the highest concentration substance present, this likely plays a large part in this process. IC contains a large amount of VLC alkyl compounds that have broken into numerous short carbon chains as shown in Figs. 7(e) and 7(f) and Figs. 8(e) and 8(f). These short chains will adsorb onto the metal surfaces physically and result in a firm physical absorption film. The long length of the alkyl chain leads to high molecular mass and van der Waals forces that cannot support the adsorption function, while short chain lengths result in low molecular masses that would strengthen the adsorption function.

\section{Conclusions}

For low workloads, epicuticular waxes have excellent friction-reducing and anti-wear properties when used as lubricant additives, compared with SE and MoDTC, and clearly enhance the function of SE. In the four waxes analyzed in this study, SJ, PI, and IC have high aliphatic compound contents, and SJ and IC performed well as lubricant additives. Iron ions, short carbon chains, and negative ions were found in the tribological films, indicating that physical and chemical adsorption films were formed during the tribological process to reduce the friction and abrasion. Cuticular waxes show high performance when utilized as lubricant additives and may be appealing alternatives to some conventional lubricant additives.

\section{Acknowledgements}

The authors appreciate the financial support for this academic work from the National Natural Science Foundation of China (No.51575181) and Beijing Natural Science Foundation (No. 2172053).

\section{Appendix}

\section{Cuticular wax contents analysis}

Gas chromatography-mass spectrometry (GC-MS) was adopted to give light to the composition of the cuticular wax mixture extracted from leaves, many ubiquitously found compounds were readily identified and the results indicated that extracts contain aliphatic, aromatic and naphthenic compounds with a large amount of oxygen containing group. To provide a comprehensive chemical analysis of the lipid mixtures which coat leaves, all compounds were quantified and the quantities and the structures of ten major wax constituents were sampled and elucidated in Tables A1, A2, A3 and A4. The data indicate that the constituents of $\mathrm{PH}$ wax are diversified heterocyclic compounds while the other three kinds of wax in which the highest content is aliphatic compound, such as VLC hydrocarbon and alcohol. Besides, some compounds are all discovered in three wax like 1, 30-Triacontanediol, 1-Octacosanol, $\beta$-Amyrin and Nonacosane.

Table A1 Compounds identified in the total wax mixtures of SJ.

\begin{tabular}{|c|c|c|c|}
\hline Abundance $[\%]$ & Chemical name & Chemical formula & Structural formula \\
\hline 24.777 & 1,30-Triacontanediol & $\mathrm{C}_{30} \mathrm{H}_{62} \mathrm{O}_{2}$ & \\
\hline 19.009 & Tetratetracontane & $\mathrm{C}_{44} \mathrm{H}_{90}$ & \\
\hline 16.002 & 1-Octacosanol & $\mathrm{C}_{28} \mathrm{H}_{58} \mathrm{O}$ & \\
\hline 6.778 & Lupeol & $\mathrm{C}_{30} \mathrm{H}_{50} \mathrm{O}$ & \\
\hline 6.532 & Heptadecyloxirane & $\mathrm{C}_{19} \mathrm{H}_{38} \mathrm{O}$ & \\
\hline 4.020 & 17-Pentatriacontene & $\mathrm{C}_{35} \mathrm{H}_{70}$ & \\
\hline 3.653 & $\beta$-Amyrin & $\mathrm{C}_{30} \mathrm{H}_{50} \mathrm{O}$ & \\
\hline
\end{tabular}


(Continued)

\begin{tabular}{|c|c|c|c|}
\hline Abundance [\%] & Chemical name & Chemical formula & Structural formula \\
\hline 2.989 & Heptacosane & $\mathrm{C}_{27} \mathrm{H}_{56}$ & \\
\hline 2.005 & Undefined substance & $\mathrm{C}_{30} \mathrm{H}_{50} \mathrm{O}$ & \\
\hline 1.966 & $\beta$-sitosterol & $\mathrm{C}_{29} \mathrm{H}_{50} \mathrm{O}$ & \\
\hline
\end{tabular}

Table A2 Compounds identified in the total wax mixtures of $\mathrm{PH}$.

\begin{tabular}{|c|c|c|c|}
\hline Abundance $[\%]$ & Chemical name & Chemical formula & Structural formula \\
\hline 18.418 & Lupeol & $\mathrm{C}_{30} \mathrm{H}_{50} \mathrm{O}$ & \\
\hline 15.159 & $\beta$-Amyrin & $\mathrm{C}_{30} \mathrm{H}_{50} \mathrm{O}$ & \\
\hline 9.593 & $\beta$-sitosterol & $\mathrm{C}_{29} \mathrm{H}_{50} \mathrm{O}$ & \\
\hline 8.851 & $\begin{array}{l}\text { Undefined } \\
\text { substance }\end{array}$ & $\mathrm{C}_{30} \mathrm{H}_{50} \mathrm{O}$ & \\
\hline 8.515 & Pentatriacontane & $\mathrm{C}_{35} \mathrm{H}_{72}$ & \\
\hline 7.481 & $\begin{array}{l}\text { Undefined } \\
\text { substance }\end{array}$ & $\mathrm{C}_{30} \mathrm{H}_{52} \mathrm{O}$ & \\
\hline 6.806 & Nonacosane & $\mathrm{C}_{29} \mathrm{H}_{60}$ & \\
\hline 3.767 & Friedelan-3-one & $\mathrm{C}_{30} \mathrm{H}_{50} \mathrm{O}$ & \\
\hline 3.489 & 1-Octacosanol & $\mathrm{C}_{28} \mathrm{H}_{58} \mathrm{O}$ & \\
\hline 3.064 & $\begin{array}{l}\text { Undefined } \\
\text { substance }\end{array}$ & $\mathrm{C}_{44} \mathrm{H}_{76} \mathrm{O}_{3}$ & \\
\hline
\end{tabular}


Table A3 Compounds identified in the total wax mixtures of PI.

\begin{tabular}{|c|c|c|c|}
\hline Abundance $[\%]$ & Chemical name & Chemical formula & Structural formula \\
\hline 20.295 & Nonacosane & $\mathrm{C}_{29} \mathrm{H}_{60}$ & \\
\hline 10.658 & 1,30-Triacontanediol & $\mathrm{C}_{30} \mathrm{H}_{62} \mathrm{O}_{2}$ & \\
\hline 7.930 & Undefined substance & $\mathrm{C}_{15} \mathrm{H}_{24}$ & \\
\hline 7.108 & 1-Tetracosanol & $\mathrm{C}_{24} \mathrm{H}_{50} \mathrm{O}$ & \\
\hline 3.481 & 1-Heptacosanol & $\mathrm{C}_{27} \mathrm{H}_{56} \mathrm{O}$ & \\
\hline 2.875 & Undefined substance & $\mathrm{C}_{21} \mathrm{H}_{30} \mathrm{O}_{2} \mathrm{~S}$ & \\
\hline 2.490 & 1-Octacosanol & $\mathrm{C}_{28} \mathrm{H}_{58} \mathrm{O}$ & \\
\hline 2.402 & 17-Pentatriacontene & $\mathrm{C}_{35} \mathrm{H}_{70}$ & \\
\hline 2.110 & Caprolactam & $\mathrm{C}_{6} \mathrm{H}_{11} \mathrm{NO}$ & \\
\hline 1.883 & Tetracosanal & $\mathrm{C}_{24} \mathrm{H}_{48} \mathrm{O}$ & \\
\hline
\end{tabular}

Table A4 Compounds identified in the total wax mixtures of IC.

\begin{tabular}{|c|c|c|c|}
\hline Abundance [\%] & Chemical name & Chemical formula & Structural formula \\
\hline 14.648 & Nonacosane & $\mathrm{C}_{29} \mathrm{H}_{60}$ & \\
\hline 14.311 & Undefined substance & $\mathrm{C}_{30} \mathrm{H}_{52} \mathrm{O}$ & \\
\hline 12.019 & Hentriacontane & $\mathrm{C}_{31} \mathrm{H}_{64}$ & \\
\hline 7.906 & Friedelan-3-one & $\mathrm{C}_{30} \mathrm{H}_{50} \mathrm{O}$ & \\
\hline 5.124 & Heptacosane & $\mathrm{C}_{27} \mathrm{H}_{56}$ & \\
\hline 2.999 & Tritriacontane & $\mathrm{C}_{33} \mathrm{H}_{68}$ & \\
\hline 3.877 & $\beta$-Amyrin & $\mathrm{C}_{30} \mathrm{H}_{50} \mathrm{O}$ & \\
\hline 1.946 & $\begin{array}{l}\text { Dodecanoic acid } \\
\text { phenylmethyl ester }\end{array}$ & $\mathrm{C}_{19} \mathrm{H}_{30} \mathrm{O}_{2}$ & \\
\hline 1.733 & 1,30-Triacontanediol & $\mathrm{C}_{30} \mathrm{H}_{62} \mathrm{O}_{2}$ & \\
\hline 1.666 & Dibutyl phthalate & $\mathrm{C}_{16} \mathrm{H}_{22} \mathrm{O}_{4}$ & \\
\hline
\end{tabular}


Open Access: The articles published in this journal are distributed under the terms of the Creative Commons Attribution 4.0 International License (http:// creativecommons.org/licenses/by/4.0/), which permits unrestricted use, distribution, and reproduction in any medium, provided you give appropriate credit to the original author(s) and the source, provide a link to the Creative Commons license, and indicate if changes were made.

\section{References}

[1] Beisson F, Li-Beisson Y, Pollard M. Solving the puzzles of cutin and suberin polymer biosynthesis. Curr Opin Plant Biol 15(3): 329-337 (2012)

[2] Barthlott W, Neinhuis C. Purity of the sacred lotus, or escape from contamination in biological surfaces. Planta 202(1): 1-8 (1997)

[3] Kerstiens G. Signalling across the divide: A wider perspective of cuticular structure-function relationships. Trends Plant Sci 1(4): 125-129 (1996)

[4] Krauss P, Markstädter C, Riederer M. Attenuation of UV radiation by plant cuticles from woody species. Plant Cell Environ 20(8): 1079-1085 (1997)

[5] Riederer M, Schreiber L. Waxes-The transport barriers of plant cuticles. In Waxes: Chemistry, Molecular Biology and Functions. Hamilton R J, Ed. West Ferry, UK: Oily Press, 1995: 131-156.

[6] Hannoufa A, McNevin J, Lemieux B. Epicuticular waxes of eceriferum mutants of Arabidopsis thaliana. Phytochemistry 33(4): 851-855 (1993)

[7] Bernard A, Joubès J. Arabidopsis cuticular waxes: Advances in synthesis, export and regulation. Prog Lipid Res 52(1): 110-129 (2013)

[8] Eglinton G, Hamilton R J. Leaf epicuticular waxes. Science 156(3780): 1322-1335 (1967)

[9] Racovita R C, Peng C, Awakawa T, Abe I, Jetter R. Very-long-chain 3-hydroxy fatty acids, 3-hydroxy fatty acid methyl esters and 2-alkanols from cuticular waxes of Aloe arborescens leaves. Phytochemistry 113: 183-194 (2015)

[10] Rashotte A M, Jenks M A, Nguyen T D, Feldmann K A. Epicuticular wax variation in ecotypes of Arabidopsis thaliana. Phytochemistry 45(2): 251-255 (1997)

[11] Shepherd T, Wynne Griffiths D. The effects of stress on plant cuticular waxes. New Phytol 171(3): 469-499 (2006)

[12] Pollard M, Beisson F, Li Y H, Ohlrogge J B. Building lipid barriers: Biosynthesis of cutin and suberin. Trends Plant Sci 13(5): 236-246 (2008)

[13] Li Y H, Beisson F. The biosynthesis of cutin and suberin as an alternative source of enzymes for the production of bio-based chemicals and materials. Biochimie 91(6): 685-691 (2009)

[14] Buschhaus C, Jetter R. Composition differences between epicuticular and intracuticular wax substructures: how do plants seal their epidermal surfaces? J Exp Bot 62(3): 841-853 (2011)

[15] Racovita R C, Hen-Avivi S, Fernandez-Moreno J P, Granell A, Aharoni A, Jetter R. Composition of cuticular waxes coating flag leaf blades and peduncles of Triticum aestivum cv. Bethlehem. Phytochemistry 130: 182-192 (2016)

[16] Busta L, Budke JM, Jetter R. Identification of $\beta$-hydroxy fatty acid esters and primary, secondary-alkanediol esters in cuticular waxes of the moss Funaria hygrometrica. Phytochemistry 121: 38-49 (2016)

[17] Xu X C, Xia Y Q, Wu H, Chen G X. The tribological properties of plant leaf extracts as lubricant additives for an aluminum-on-steel contact. Chin Sci Bull 59(36): 3621-3625 (2014)

[18] Xia Y Q, Xu X C, Feng X, Chen G X. Leaf-surface wax of desert plants as a potential lubricant additive. Friction 3(3): 208-213 (2015)

[19] Shi Q Y, Xia Y Q, Feng X. Lubricant adding with wheat leaf surface wax improving friction performance of steel/ copper friction pair. Trans Chin Soc Agric Eng 32(15): 54-59 (2016)

[20] Sodhi R N S. Time-of-flight secondary ion mass spectrometry (TOF-SIMS): - versatility in chemical and imaging surface analysis. Analyst 129(6): 483-487 (2004)

[21] Castro W, Perez J M, Erhan S Z, Caputo F. A study of the oxidation and wear properties of vegetable oils: soybean oil without additives. J Am Oil Chem Soc 83(1): 47-52 (2006)

[22] Hsu S M. Molecular basis of lubrication. Tribol Int 37(7): 553-559 (2004)

[23] Antusch S, Dienwiebel M, Nold E, Albers P, Spicher U, Scherge M. On the tribochemical action of engine soot. Wear 269(1-2): 1-2 (2010)

[24] Studt P. Boundary lubrication: Adsorption of oil additives on steel and ceramic surfaces and its influence on friction and wear. Tribol Int 22(2): 111-119 (1989)

[25] Wan Y, Liu W M, Xue Q J. Effects of diol compounds on the friction and wear of aluminum alloy in a lubricated aluminum-on-steel contact. Wear 193(1): 99-104 (1996) 


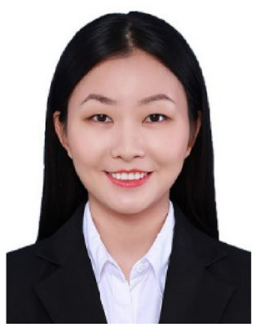

Xuwen ZHONG. She received her bachelor degree in mechanical engineering and automation in 2015 from North China Electric Power University, Beijing China. Now,

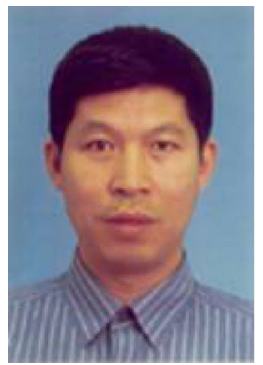

Yanqiu XIA. He received his PHD from Northeastern University in 1999, and was selected as Hundreds Talent Program of Chinese Academy of Science Professor in 2007. He joined the School of Energy Power she is a master student majoring in mechanical design and theory. She is about to graduate from the same university in 2018. Her research interest is environment-friendly lubricants and additives.

and Mechanical Engineer, North China Electric Power University in 2010. His current position is the professor. His research areas cover tribology of mechanical and electrical equipment, focusing on lubricants, greases, additives and tribochemistry. 